\title{
Amelioration of Albuminuria in ROCK1 Knockout Mice with Streptozotocin-Induced Diabetic Kidney Disease
}

\author{
Li Zhou $^{a}$ Fei Liu ${ }^{a}$ Xiao R. Huang ${ }^{b}$ Fang Liu $^{a}$ Haiyong Chen ${ }^{b}$ \\ Arther C.K. Chung ${ }^{b}$ Jianjian Shic ${ }^{c}$ Lei Wei $^{c}$ Hui Y. Lan ${ }^{b}$ Ping Fu ${ }^{a}$

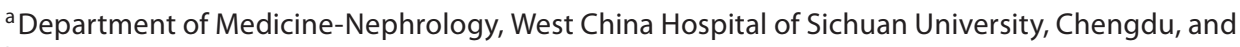 \\ ${ }^{b}$ Department of Medicine and Therapeutics, and Li Ka Shing Institute of Health Sciences, The Chinese University \\ of Hong Kong, Hong Kong, SAR, China; ' $R i l e y$ Heart Research Center, Wells Center for Pediatric Research, \\ Indiana University School of Medicine, Indianapolis, Ind., USA
}

\section{Key Words}

Diabetic kidney disease $\cdot$ Tubular cells, albuminuria .

ROCK $\cdot$ Megalin $\cdot$ Cubilin

\begin{abstract}
Background: Although blockade of Rho kinase with pharmacologic inhibitors ameliorates renal fibrosis and diabetic kidney disease (DKD), the underlined mechanisms remain largely unclear. The present study tested the hypothesis that ROCK1 may regulate the early development of albuminuria via the megalin/cubilin-dependent mechanism. Methods: A DKD model was induced in ROCK1 knockout and wild-type mice by streptozotocin (STZ). The effect of deleted ROCK1 on urinary albumin excretion and the expression of megalin/ cubilin were examined. In addition, the effect of blocking ROCK activities with an inhibitor (Y-27632) on tubular albumin reabsorption was tested in a normal rat tubular epithelial cell line (NRK52E) under high-glucose conditions. Expression of transforming growth factor (TGF)- $\beta 1$, interleukin- $1 \beta$ and collagen-1 was also been examined. Results: Urinary albumin excretion was significantly increased in ROCK1 WT mice at 8 weeks after STZ injection. In contrast, mice lacking ROCK1 gene were protected against the development of albuminuria. This was associated with the protection against the loss of megalin/cubilin and an increase in TGF- $\beta_{1}, \mathrm{IL}-1 \beta$,
\end{abstract}

and fibrosis in the kidney. In vitro, we also found that blockade of Rho kinase with inhibitor Y-27632 prevented high-glucose-induced loss of megalin expression and an increase of TGF- $\beta_{1}$, thereby increasing the absorption rate of FITC-labeled albumin by tubular epithelial cells. Conclusion: ROCK1 may play a role in the development of albuminuria in DKD by downregulating the endocytosis receptors complex - megalin/cubilin.

Copyright $\odot 2011$ S. Karger AG, Basel

\section{Introduction}

Type 2 diabetes mellitus is a global epidemic disease and is the leading cause of end-stage renal disease. Diabetic kidney disease (DKD) occurs in approximately 20$30 \%$ of all diabetic subjects, representing a continuum from microalbuminuria to the overt nephropathy or macroalbuminuria, and finally end-stage renal disease [1]. However, the underlined mechanisms of the pathogenesis of microalbuminuria in the early stage of DKD remain largely unclear.

Increasing evidence shows that albuminuria is a marker and mediator for progressive DKD and is associated with decreased albumin endocytosis that is mediated by dysregulation of megalin expression [2]. Reduced megalin-

\section{KARGER}

๑) 2011 S. Karger AG, Basel

Fax +4161306 1234

E-Mail karger@karger.ch

www.karger.com
Accessible online at: www.karger.com/ajn
Prof. Ping Fu

Department of Medicine-Nephrology

West China Hospital of Sichuan University

Chengdu 610041 (China)

Tel. +86 1898060 1201, E-Mail fupinghx@163.com 
and cubilin-mediated endocytosis of albumin has been induced by transforming growth factor (TGF)-1 in vitro in proximal-tubule-derived opossum kidney cells [3].

Activation of Rho kinase has been verified in DKD [4, 5] and pharmacologic inhibition of Rho kinase has been shown to be protective against DKD [6]. As a potential mediator of renal disease, Rho and its downstream effectors, Rho-associated coiled coil-forming protein serine/ threonine kinase (Rho kinase or ROCK), has been well studied in a variety of cellular responses [7, 8], including cell adhesion, actin dynamics and regulation of gene transcription. In addition, Rho kinase has also been shown to play a critical role in endocytosis, epithelialmesenchymal transition, and fibrosis [9].

In the present study, we tested a hypothesis that the development of albuminuria in the early stage of DKD may occur via the mechanism of Rho kinase-induced loss of megalin/cubilin-mediated endocytosis of albumin by tubular epithelial cells. This hypothesis was examined in a mouse diabetic model induced in ROCK1 gene knockout mice by streptozotocin (STZ) and in vitro by blocking Rho kinase with a pharmacological inhibitor.

\section{Materials and Methods}

Animal Model of DKD Induced in ROCK1 Knockout Mice by STZ

Characterization of ROCK1 knockout (KO) and wild-type (WT) mice (FVB background) has been described previously [10]. Deletion of ROCK1 from the kidney was confirmed by Western blot as previously described [11] (fig. 1a).

A mouse DKD model was induced in littermate ROCK1 WT and KO mice (20-30 g body weight, 2 months of age) by STZ (Sigma-Aldrich, St. Louis, Mo., USA) $50 \mathrm{mg} / \mathrm{kg}$ intraperitoneally for 5 consecutive days as recommended by AMDCC (Brosius 2009). Fasting blood glucose taken from the tail was monitored by blood glucose meter (Optium Xceed ${ }^{\mathrm{TM}}$ Diabetes Monitoring System, Vic., Australia) every 2 weeks. Control mice were injected with the citrate buffer. Groups of 6 mice were killed on week 8 after STZ or citrate buffer injection. Samples of renal cortex were collected for histology, immunohistochemistry, Western blot, and real-time PCR analyses. Urine samples were collected after $16 \mathrm{~h}$ for the assay of urinary albumin excretion.

\section{Urinary Albumin Excretion Assay}

Urinary albumin excretion was measured by competitive ELISA as recommended by AMDCC (Brosius 2009). Briefly, albumin at a concentration of $5 \mu \mathrm{g} / \mathrm{ml}$ in PBS was coated in an ELISA plate (MaxiSorp Surface Immuno Plates ${ }^{\mathrm{TM}}$; Nunc, Roskilde, Denmark) overnight. After PBS washing three times, $100 \mu \mathrm{l}$ of a standard (albumin $0.2-25 \mu \mathrm{g} / \mathrm{ml}$; ICN Biomedicals, Aurora, Ohio, USA) or urine sample (diluted 1:20) were added into the wells together with anti-albumin antibody (1:5,000; ICN Biomedicals) shaking at room temperature for $1 \mathrm{~h}$. After extended washing, ABTS was added into wells for full developing while avoiding light. OD values were read at $410 \mathrm{~nm}$ and concentrations were automatically calculated by a program according to the standard curve.

\section{Histology and Immunohistochemistry}

Changes in histology were examined in methyl Carnoy-fixed, paraffin-embedded tissue sections $(3 \mu \mathrm{m})$. To evaluate the kidney fibrosis (collagen accumulation), picrosirius red and fast green staining were used in paraffin-embedded kidney sections. Highpower fields $(\times 400)$ of renal cortex were randomly scanned by using a microscope equipped with a digital camera, and quantitative evaluation was performed with Image-Pro software (MediaCybernetics, Inc., Silver Spring, Md., USA). The scores of 5-7 separate mice in each group were averaged.

A microwave-based antigen retrieval method was used for immunohistochemistry as described previously [12]. After being microwaved, sections were incubated with rabbit polyclonal antibody to cubilin (Santa Cruz Biotechnology, Santa Cruz, Calif., USA) using a two-layer peroxidase anti-peroxidase method. Sections were developed with diaminobenzidine, counterstained with hematoxylin, and coverslipped in an aqueous mounting medium. An isotype rabbit IgG (Sigma) was used as negative control in the study.

\section{Western Blot Analyses}

Protein from kidney cortex was extracted with RIPA lysis buffer for Western blot analysis as described previously $[3,13]$. Briefly, samples were heated at $99^{\circ} \mathrm{C}$ for $10 \mathrm{~min}$, loaded into wells of $7-20 \%$ gel and then transferred to a nitrocellular membrane. Non-specific binding to the membrane was blocked for $1 \mathrm{~h}$ at room temperature with $5 \%$ fat-free milk in Tris-buffered saline buffer. The membranes were then incubated overnight at $4{ }^{\circ} \mathrm{C}$ with primary antibodies, including rabbit antibody against megalin, cubilin, ROCK 1 and TGF- $\beta_{1}$ (Santa Cruz Biotechnology), and glyceraldehyde-3-phosphate dehydrogenase (GAPDH; Chemicon, Temecula, Calif., USA). After washing, the membrane was incubated with an IRDye-800-conjugated goat anti-rabbit or rabbit anti-mouse antibody (Rockland Immunochemicals, Gilbertsville, Pa., USA) diluted 1:20,000 in 5\% fat-free milk in TBST for 1 $\mathrm{h}$ and signals were detected using an Odyssey Infrared Imaging System (Li-COR Biosciences, Lincoln, Nebr., USA).

\section{Real-Time PCR}

Total RNA from renal cortex or cells was isolated using the RNeasy kit, according to the manufacturer's instructions (Qiagen, Valencia, Calif., USA). Real-time PCR was run with the Opticon real-time PCR machine (MJ Research, Waltham, Mass., USA) as previously described [14]. The specificity of real-time PCR was confirmed via the melting-curve analysis. Housekeeping gene GAPDH was used as an internal standard. The primers used in this study are as follows: megalin (mouse), forward $5^{\prime}$ AGGCCACCAGTTCACTTGCT-3', reverse 5'-AGGACACGCCCATTCTCTTG-3'; cubilin (mouse), forward 5'-GGGATCCTCTCAGGGACACA-3', reverse 5'-TGCTGGCCGATTCTAAATCAA-3'; TGF- $\beta_{1}$ (mouse): forward 5'-CAACAATTCCTGGCGTTACCTTGG-3', reverse 5'-GAAAGCCCTGTATTCCGTCTCCTT-3'; IL-1 $\beta$ (mouse): forward 5'-CTTCAGGCAGGCAGTATCACTCAT-3', reverse 5'-TCTAATGGGAACGTCACACACCAG; GAPDH (mouse), forward 5'-TGCTGAGTATGTCGT- 


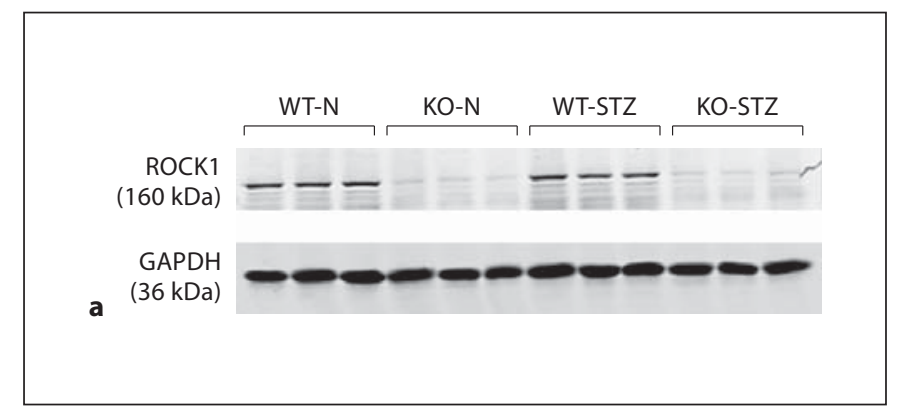

Fig. 1. ROCK1 KO mice are protected against the development of albuminuria in a mouse model of diabetes. a Evidence for deletion of ROCK1 gene in mice. Western blot shows undetectable ROCK1 protein obtained from kidneys of ROCK1 gene KO mice. Each lane represents 1 mouse. b Fasting blood glucose. c Levels of urinary albumin excretion (UAE). Data show that the development of albuminuria is prevented in ROCK1 KO mice with diabetes at 8 weeks after STZ injection. Each bar represents the mean \pm SEM for 6 mice of one group. ${ }^{* *} \mathrm{p}<0.01$ compared to control mice; ${ }^{\#} \mathrm{p}<0.05$ compared to WT mice treated with STZ.

GGAGTCTA-3' and reverse 5'-AGTGGGAGTTGCTGTTGAAATC-3'; megalin (rat), forward 5'-ACCGCCGCAATGCCGCTGACT-3', reverse 5'-TGCCCCAATGCCATAGGTAACGA-3'; GAPDH (rat), forward 5'-CCTGGAGAAACCTGCCAAGTATGA-3' and reverse 5'-TTGAAGTCACAGGAGACAACCTGG$3^{\prime}$. Ratios to GAPDH were calculated for each sample and expressed as means \pm SEM.

\section{In vitro Studies}

To study the mechanism of ROCK1 in the process of endocytosis, a well-characterized normal rat kidney TEC line (NRK52E) was used. NRK52E cells were grown in low-glucose $(5 \mathrm{mmol} / \mathrm{l})$ Dulbecco's modified Eagle's medium (Hyclone, Logan, Utah, USA) containing $5 \%$ fetal bovine serum, $60 \mu \mathrm{g} / \mathrm{ml}$ penicillin, and $100 \mu \mathrm{g} / \mathrm{ml}$ streptomycin in a $5 \% \mathrm{CO}_{2}$ atmosphere at $37^{\circ} \mathrm{C}$. After $24 \mathrm{~h}$ starvation with serum-free DMEM-low glucose, DMEMhigh glucose (25 mmol/l) was used for culture of $0,3,6,12,24$ or $72 \mathrm{~h}$. Cells cultured with DMEM-low glucose was used as control and mannitol at concentration of $25 \mathrm{mmol} / \mathrm{l}$ was used as osmotic control. To investigate the role of Rho kinase under high-glucose conditions, a ROCK pharmacological inhibitor, Y-27632 (Sigma-Aldrich), was added into the cells $(1 \mu \mathrm{M}) 1 \mathrm{~h}$ before highglucose stimulation.

Flow Cytometry of FITC-Albumin for the Assay of Cell Endocytosis

After treatment with high glucose for $72 \mathrm{~h}$, FITC-albumin (Sigma-Aldrich) diluted to $10 \mu \mathrm{g} / \mathrm{ml}$ in DMEM-low glucose was added into 6 -well plates at $37^{\circ} \mathrm{C}$ for $30 \mathrm{~min}$. Control cells were incubated with FITC-albumin at $4^{\circ} \mathrm{C}$ for $30 \mathrm{~min}$. The cells were then trypsinized and washed with PBS twice before they were analyzed with a Cytomics FC 500 Flow Cytometer (Beckman Coulter Inc., Fullerton, Calif., USA). For all the above processes, light was avoided. Mean intensity of fluorescence minus back-
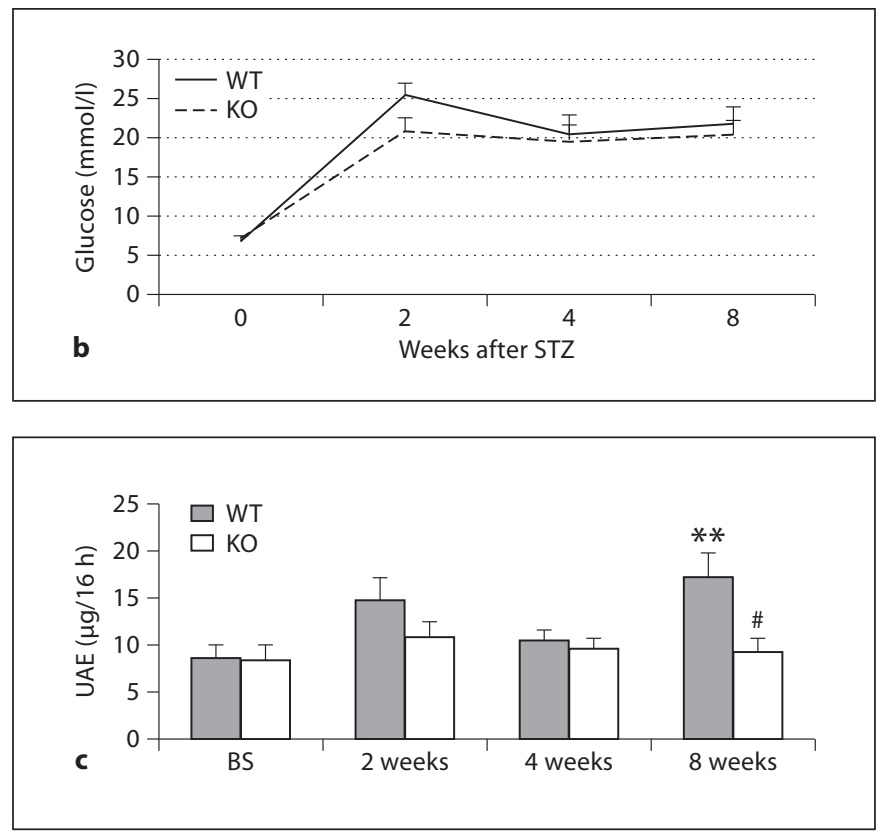

ground binding of FITC at $4{ }^{\circ} \mathrm{C}$ was recorded as the FITC-albumin phagocytosed by cells.

\section{Statistical Analyses}

Data obtained from this study are expressed as the mean \pm SEM of at least three independent experiments or 6 mice from one group of mice. Statistical analyses were performed using one-way analysis of variance followed by Newman-Keuls post-test using the GraphPad Prism 4.0 (GraphPad Software, Inc., San Diego, Calif., USA).

\section{Results}

\section{ROCK1 KO Mice Are Protected against Albuminuria in STZ-Induced Diabetic Mice}

Characterization of ROCK1 KO mice was confirmed by absence of ROCK1 protein expression detected by Western blot analysis (fig. 1a). A mouse model of diabetes was successfully induced by STZ in both ROCK1 WT and $\mathrm{KO}$ mice as demonstrated by an equal level of increased blood glucose (fig. 1b). However, while ROCK1 WT mice developed a significant albuminuria at 8 weeks after STZ injection, ROCK1 KO mice had a normal level of urinary albumin excretion throughout the disease course (fig. 1c).

\section{Deletion of ROCK1 Prevents a Loss of}

Megalin/Cubilin in Kidneys with Diabetes

We then examined the potential mechanisms by which ROCK1 KO mice were protected against the development 


\section{Color illustration online only!}

Fig. 2. Downregulation of magalin/cubilin expression in the diabetic kidney is prevented in ROCK1 KO mice. a Real-time PCR shows that reduced megalin/cubilin expression in kidneys is attenuated in ROCK1 KO mice treated with STZ at 8 weeks. b Western blots show that reduced cubilin expression in the renal cortex is attenuated in ROCK1 KO mice treated with STZ at 8 weeks. c Immunohistochemistry of cubilin shows that reduced cubilin expression in the renal cortex is attenuated in ROCK1 KO mice treated with STZ at 8 weeks: (i) representative WT control mouse; (ii) representative ROCK1 KO control mouse; (iii) representative WT mouse treated with STZ, and (iv) representative ROCK1 KO mouse treated with STZ. Each lane represents 1 mouse. Each bar represents mean \pm SEM for a group of 6 mice. ${ }^{*} \mathrm{p}<0.05,{ }^{* *} \mathrm{p}<0.01,{ }^{* * *} \mathrm{p}<0.001 \mathrm{com}-$ pared to control mice; ${ }^{\#} \mathrm{p}<0.01$, \#\# $\mathrm{p}<$ 0.001 compared to WT mice treated with STZ. $\times 200$.
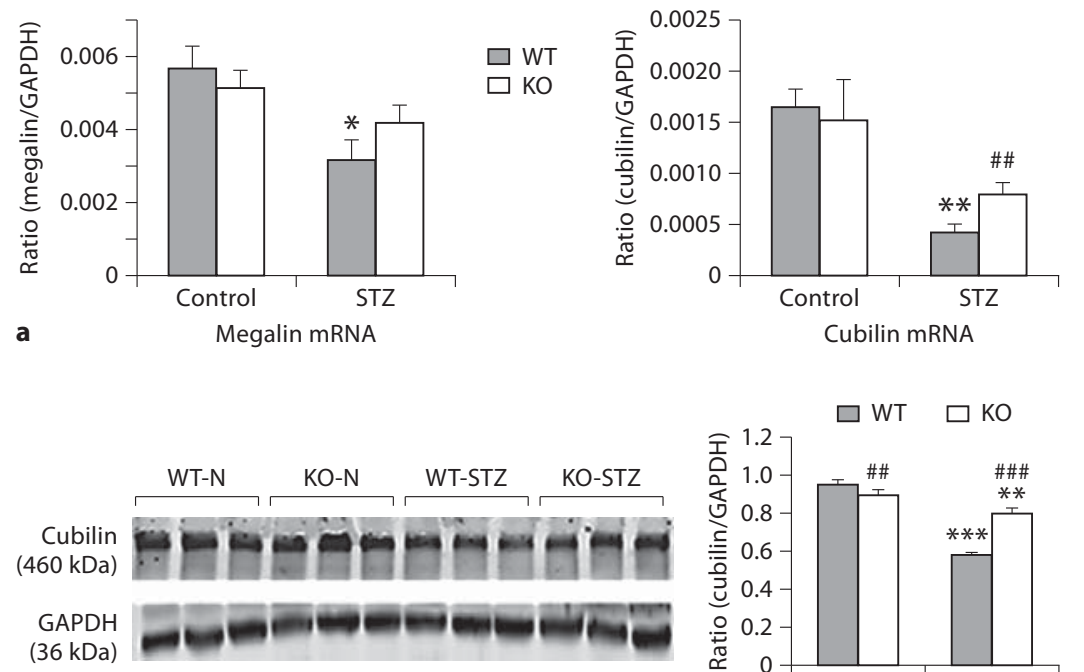

b
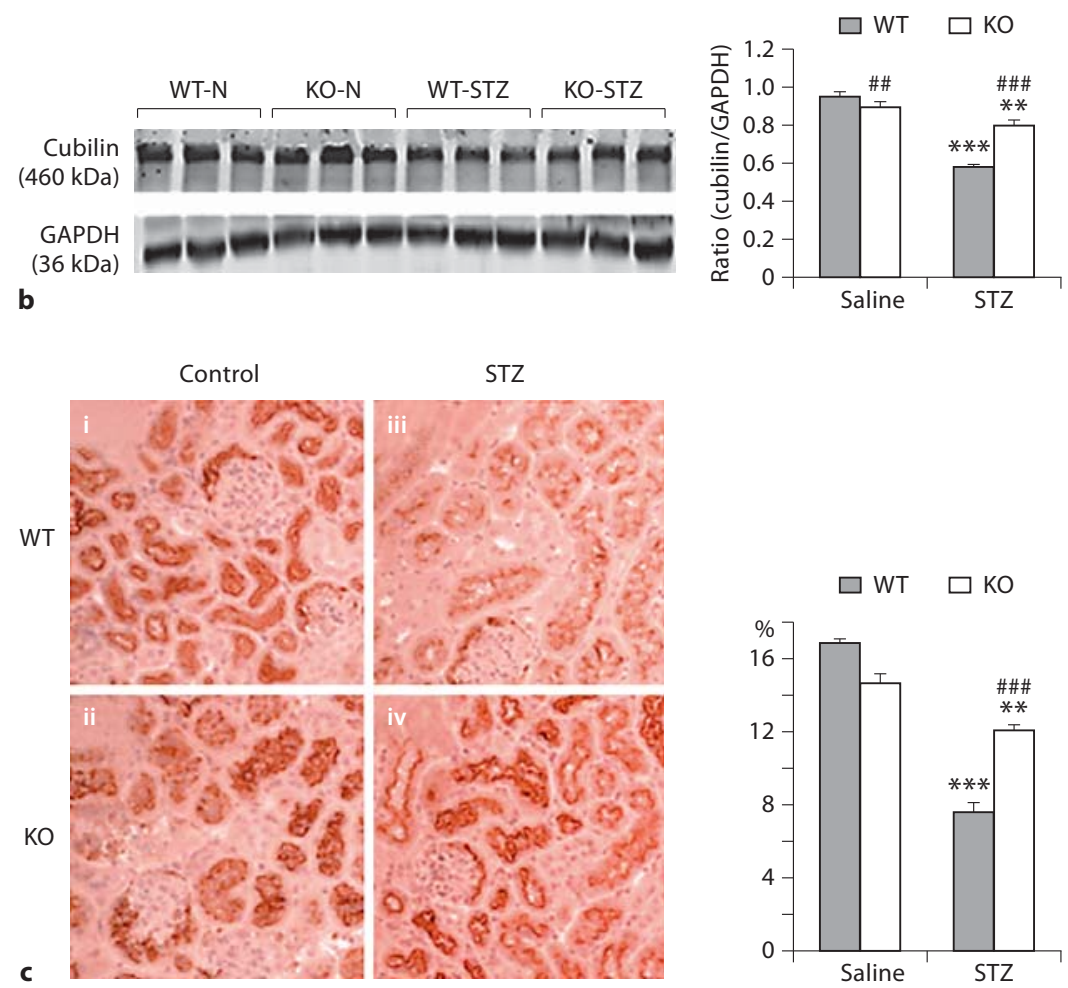

of albuminuria in diabetes by examining expression of megalin/cubilin in the cortex of kidneys. Analysis using real-time PCR, Western blot, and immunohistochemistry showed expressions of megalin and cubilin by tubular epithelial cells, presumably as proximal tubular epithelial cells were largely reduced in Wt mice with diabetes. In contrast, diabetic mice lacking ROCK1 gene exhibited normal expression levels of megalin and cubilin (fig. 2ac). Interestingly, Western and real-time PCR showed that deletion of ROCK1 resulted in a significant inhibition of TGF- $\beta_{1}$ mRNA and protein expression in the diabetic kidney (fig. 3a, b). Meanwhile, the same changes were also found in expression of IL-1 $\beta$ mRNA and collagen matrix accumulation in the diabetic kidney (fig. $3 c, d$ ).

\section{ROCK Inhibitor Y-27632 Inhibits}

High-Glucose-Induced Loss of Megalin, Increases

Cytophagosis of Albumin, and Blocks Upregulation of TGF- $\beta_{1}$ by NRK52E in vitro

To explore the mechanism of the functional role of ROCK1 in the development of albuminuria in DKD, we performed in vitro studies in a NRK52E rat tubular epithelial cell line under conditions of high glucose and in the presence or absence of a ROCK inhibitor Y-27632. As shown in figure 4 , high glucose $(25 \mathrm{mM})$, but not mannitol control, induced a significant loss of megalin at the mRNA level at $6 \mathrm{~h}$ (fig. $4 \mathrm{a}$ ) and the protein level at $24 \mathrm{~h}$ (fig. 4b), which was prevented by a ROCK inhibitor Y-27632 (1 $\mu \mathrm{M})$ (fig. 4a, b). Furthermore, using flow cy- 
Fig. 3. Deletion of ROCK1 inhibits upregulation of renal TGF- $\beta_{1}$, IL- $1 \beta$ and renal fibrosis in a mouse model of diabetes. a, b TGF- $\beta_{1}$ mRNA and protein expression detected by Western blot and realtime PCR. c IL-1 $\beta$ mRNA expression by real-time PCR. d Renal fibrosis examined by picrosirius red and fast green staining. Results show that deletion of ROCK1 inhibits upregulation of renal TGF- $\beta_{1}$, IL$1 \beta$, and the development of tubulointerstitial fibrosis in the diabetic kidney at 8 weeks after STZ treatment. Each bar represents mean \pm SEM for a group of 6 mice. ${ }^{*} \mathrm{p}<0.05,{ }^{* *} \mathrm{p}<0.01$ compared to control mice; ${ }^{\#} \mathrm{p}<0.05$, \#\# $\mathrm{p}<0.01$ compared to WT mice treated with STZ. $\times 400$.

Fig. 4. ROCK inhibitor Y-27632 blocks high-glucose-induced loss of megalin expression by NRK52E cells. a Real-time PCR shows that: (i) high glucose induces a loss of megalin expression at $6 \mathrm{~h}$, and (ii) high-glucose-induced loss of megalin at $6 \mathrm{~h}$ is prevented by an addition of ROCK inhibitor Y-27632 $(1 \mu \mathrm{M})$. b Western blot analysis shows that an addition of ROCK inhibitor Y-27632 (1 $\mu \mathrm{M})$ inhibits a loss of megalin induced by high glucose at $72 \mathrm{~h}$. Each bar represents mean \pm SEM for three independent experiments. ${ }^{*} \mathrm{p}<0.05$, compared to low-glucose control; ${ }^{\#} \mathrm{p}<$ 0.05 , compared to high-glucose group.
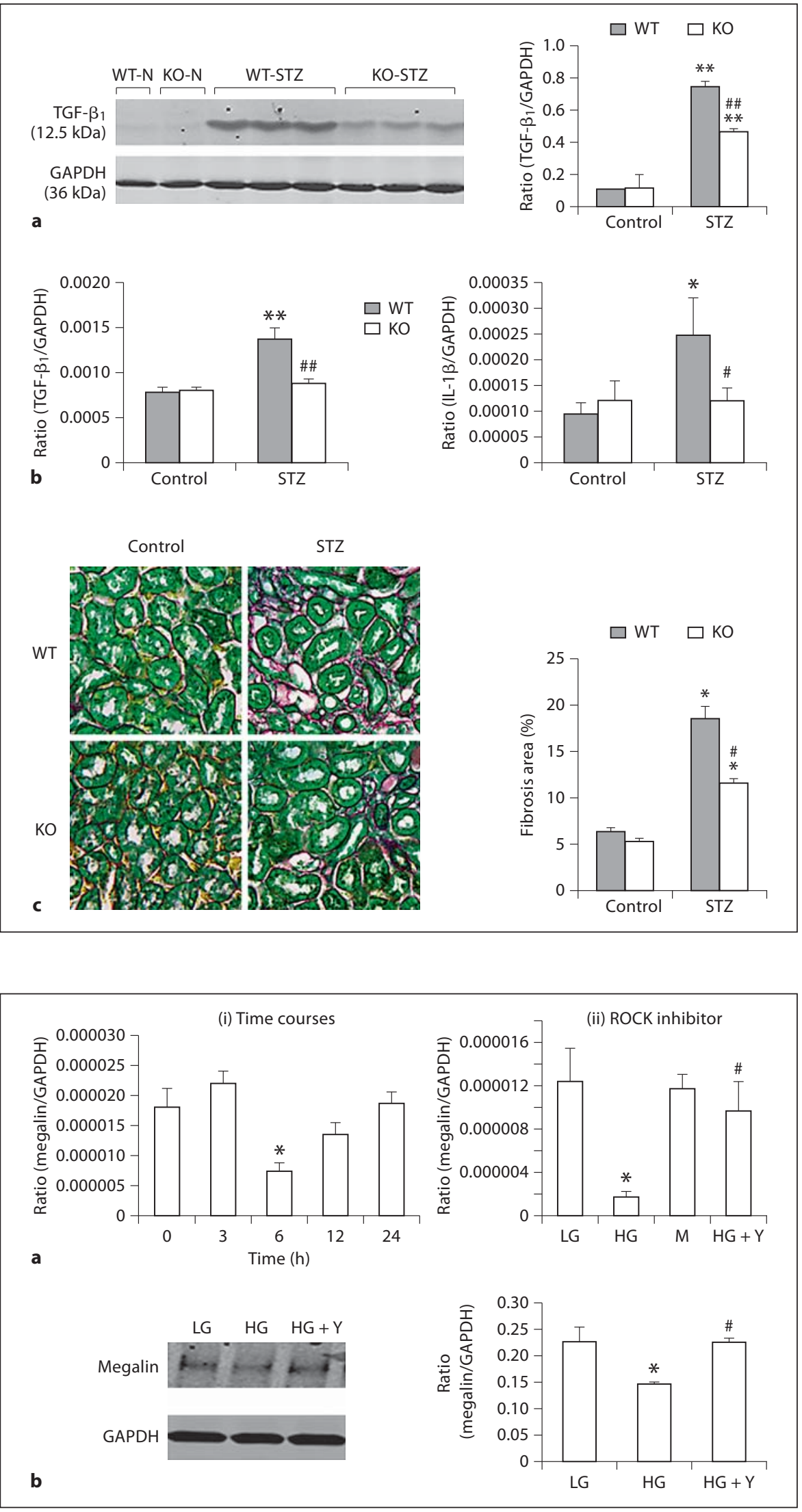
Fig. 5. ROCK inhibitor Y-27632 blocks high-glucose-induced impairment of albumin uptake by NRK52E cells and upregulation of TGF- $\beta_{1}$. a Flow cytometry (i, ii): Endocytosis assay with FITC-labeled albumin shows that high glucose impairs the endocytosis of FITC-labeled albumin by tubular epithelial cells induced by high glucose at $72 \mathrm{~h}$, which is inhibited by an addition of a ROCK inhibitor Y-27632 $(1 \mu \mathrm{M})$. b Western blot analysis shows that an addition of ROCK inhibitor Y-27632 $(1 \mu \mathrm{M})$ inhibits high-glucose-induced upregulation of TGF- $\beta_{1}$ by tubular epithelial cells at $72 \mathrm{~h}$. Each bar represents mean \pm SEM for three independent experiments. ** $p<0.01$ compared to low-glucose control; ${ }^{\#} \mathrm{p}<0.05,{ }^{\# \#} \mathrm{p}<0.01$ compared to the high-glucose group.
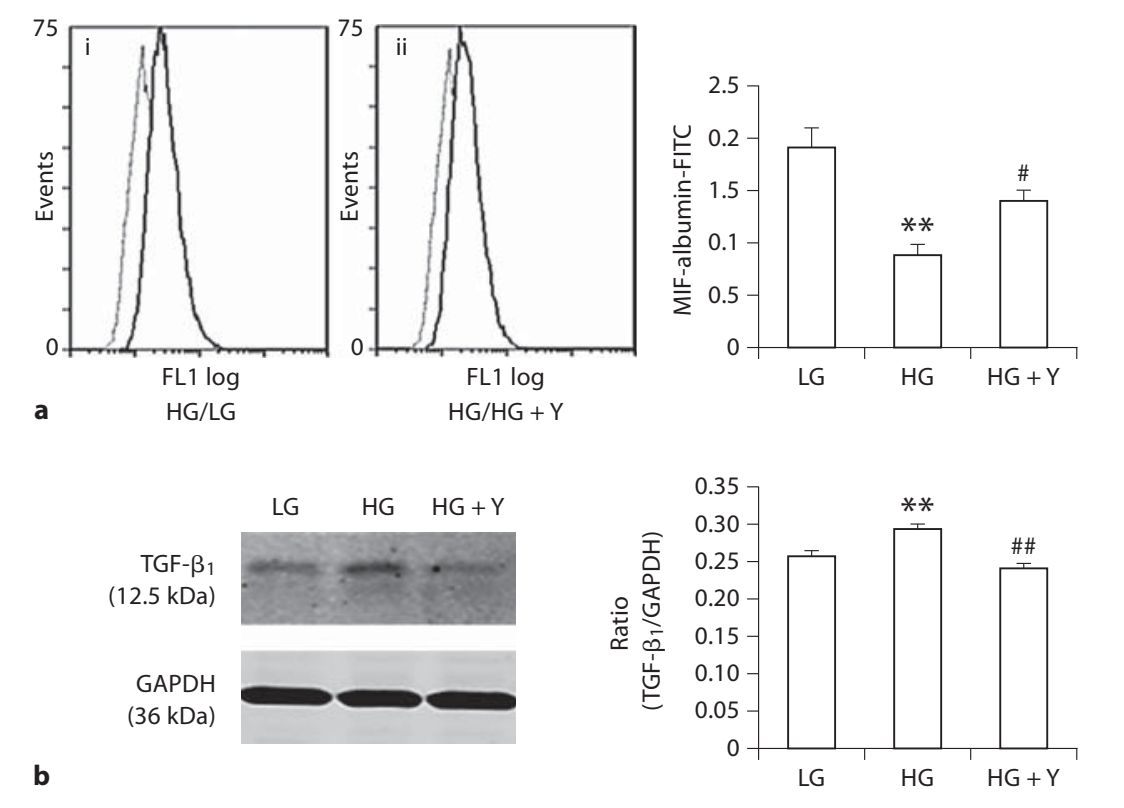

tometry, we also demonstrated that high glucose was able to impair cytophagosis of FITC-albumin by NRK52E tubular epithelial cells, which was prevented by addition of ROCK inhibitor (fig. 5a). Interestingly, high-glucose-induced upregulation of TGF- $\beta_{1}$ was also blocked by a ROCK inhibitor (fig. 5b).

\section{Discussion}

This study showed that deletion of ROCK1 protected against the development of albuminuria in a mouse model of DKD induced by STZ. This finding is consistent with the protective effect of ROCK inhibitor, fasudil, in a STZinduced mouse model and in $\mathrm{db} / \mathrm{db}$ mice $[5,6,15]$. The novel finding from the present study was that Rho kinase mediated albuminuria via the megalin/cubilin-dependent mechanism because prevention from the development of albuminuria in the ROCK1 KO mice was associated with the protection against the loss of megalin/cubilin in DKD mice. Indeed, the development of albuminuria in the early stage of diabetic mice has been shown to be associated with the decrease in albumin endocytosis by tubular epithelial cells due to lower levels of megalin expression as demonstrated by using a functional micropuncture and an immunogold electron microscope technique [2]. It is now clear that the process of reabsorption of albumin from the glomerular filtrate is via the mechanism of receptor-medi- ated endocytosis by proximal tubular epithelial cells. Megalin/cubilin are members of the low-density lipoprotein receptor family [16] and have been shown to mediate endocytosis of multiple, unrelated ligands via coated pits, leading to delivery of ligands to lysosomes. After binding of albumin to the megalin/cubilin complex in apical alathrin-coated pits, the endocytosis of albumin occurs, followed by degradation in lysosomes. By immunohistochemistry, megalin and cubilin have been found on the apical surface of a restricted group of absorptive epithelial cells, including tubular epithelial cells [17, 18]. Reduced expressions of megalin/cubilin have been found in association with the development of albuminuria in aristolochic acid nephropathy [19], Dent's disease [20] and autosomaldominant polycystic kidney disease [21]. Thus, protection from a loss of megalin and cubilin in the diabetic mouse kidney could be a key mechanism by which ROCK1 KO mice were protected against the development of albuminuria. This was further supported by the in vitro finding that blockade of Rho kinase with addition of Rho kinase inhibitor rescued a loss of megalin, thereby resulting in an increased absorption rate of FITC-albumin by tubular epithelial cells under high-glucose conditions in vitro. Indeed, proteinuria is the most important predictor of clinical outcomes in both diabetic and non-diabetic nephropathy $[22,23]$. A Rho kinase-mediated loss of megalin/ cubilin-dependent endocytosis of albumin could be a mechanism of the development of albuminuria. Once al- 
buminuria occurs, it can activate the 'albumin-regulated genes' to mediate tubulointerstitial fibrosis as reported recently using Affymetrix microarray [24].

Inhibition of TGF- $\beta_{1}$ expression may be another mechanism by which deletion of ROCK1 prevented the development of albuminuria in diabetic mice and the impairment of albumin endocytosis by tubular epithelial cells. This was supported by the findings that ROCK1 KO mice had lower levels of TGF- $\beta_{1}$ but higher levels of megalin/cubilin expression in the diabetic kidney and that blockade of Rho kinase activities with a specific inhibitor inhibited high-glucose-induced TGF- $\beta_{1}$ expression and rescued a loss of megalin-mediated albumin uptake by tubular epithelial cells. These findings are consistent with a previous report that addition of TGF- $\beta_{1}$ inhibits megalin/cubilin-dependent endocytosis of albumin in proximal tubular epithelial cells derived from opossum kidney cells [3]. It has been shown that albumin is able to activate TGF- $\beta$ signaling and collagen IV expression by proximal tubular cells [25], suggesting a positive regulatory loop among 'TGF- $\beta_{1}$-megalin/cubulinalbuminuria' during the development of tubulointerstitial fibrosis. Thus, activation of Rho kinase may impair megalin/cubulin-mediated endocytosis of albumin by tubular epithelial cells and results in the development of albuminuria, which, in turn, upregulates TGF- $\beta$ to mediate renal fibrosis. A role of Rho kinase in TGF- $\beta$-mediated diabetic kidney injury is further demonstrated by a recent study that fasudil treatment is capable of suppressing upregulation of renal TGF- $\beta_{1}$ and CTGF, thereby inhibiting renal fibrosis including collagen I and fibronectin expression and, particularly, the epithelial-mesenchymal transition in STZ-induced, uninephrectomized diabetic rats [26]. Thus, inhibition of TGF- $\beta$-mediated renal fibrosis may be a mechanism by which treatment of Rho kinase inhibitor ameliorates albuminuria in both type 1 and type 2 diabetes $[5,6,26,27]$. Results from the present study in ROCK1 KO mice provided further evidence for supporting this notion.

Albuminuria is able to activate the inflammatory pathway and induces chemokine and cytokine expression [28]. We also found that inhibition of albuminuria and protection of megalin/cubulin from a loss in diabetic ROCK1 KO mice were also associated with suppression of IL- $1 \beta$ expression, suggesting that the activation of the inflammatory pathway may downregulate megalin/cubilin-dependent endocytosis of albumin in the early stage of DKD. Therefore, inhibition of renal inflammation could also be a mechanism by which ROCK1 KO mice were protected against the early diabetic kidney injury.
ROCK1 and ROCK2 are isoforms of Rho kinase, both of which are active and play an important role in cytoskeletal arrangement $[7,8]$, cardiovascular remodeling [29, $30]$, liver fibrosis $[31,32]$, epithelial-mesenchymal transition [33-35] and in renal injury such as tubulointerstitial fibrosis in the mouse model of unilateral ureteral obstruction nephropathy [36, 37], ischemia/reperfusion-induced acute renal failure [38], and glomerulosclerosis in spontaneous hypertensive rats [39]. Studies on ROCK1 KO mice have provided new insights into the role of ROCK1 and ROCK2 in the physiopathological process. It is noticed that ROCK1 KO has a protective role on ischemia/reperfusion cardiomyopathy [40] and cardiac hypertrophic decompensation [41]. Loss of ROCK2 results in placental dysfunction leading to intrauterine growth retardation and fetal death. It has also been reported mice deficient of ROCK1 at 16-18 weeks of age may develop insulin resistance [42]. However, our results with equally high levels of blood glucose in both ROCK1 KO and WT mice over an 8-week period suggest that a longer diabetic time course may be necessary for studying the role of Rho kinase in diabetic kidney complications.

\section{Acknowledgements}

This study was supported by grants from the National Natural Science Foundation of China (30871165), the Research Grant Council of Hong Kong (RGC GRF 768207 and N_CUHK404/10), the Showalter Trust (89829) and the National Institutes of Health (HL085098) of the United States.

\section{Disclosure Statement}

The authors have no conflicts of interest to disclose.

References $\quad D_{1}$ Soldatos G, Cooper ME: Diabetic nephropathy: important pathophysiologic mechanisms. Diabetes Res Clin Pract 2008;82 (suppl 1):S75-S79.

2 Tojo A, Onozato ML, Ha H, Kurihara $\mathrm{H}$, Sakai T, Goto A, Fujita T, Endou H: Reduced albumin reabsorption in the proximal tubule of early-stage diabetic rats. Histochem Cell Biol 2001;116:269-276.

-3 Gekle M, Knaus P, Nielsen R, Mildenberger S, Freudinger R, Wohlfarth V, Sauvant C, Christensen EI: Transforming growth factor- $\beta_{1}$ reduces megalin- and cubilin-mediated endocytosis of albumin in proximal-tubule-derived opossum kidney cells. J Physiol 2003;552:471-481. 
4 Ishibashi F: High glucose increases phosphocofilin via phosphorylation of LIM kinase due to Rho/Rho kinase activation in cultured pig proximal tubular epithelial cells. Diabetes Res Clin Pract 2007;80:24-33.

5 Kolavennu V, Zeng L, Peng H, Wang Y, Danesh FR: Targeting of RhoA/ROCK signaling ameliorates progression of diabetic nephropathy independent of glucose control. Diabetes 2008;57:714-723.

6 Kikuchi Y, Yamada M, Imakiire T, Kushiyama T, Higashi K, Hyodo N, Yamamoto K, Oda T, Suzuki S, Miura S: A Rho-kinase inhibitor, fasudile, prevents development of diabetes and nephropathy in insulin-resistant diabetic rats. J Endocrinol 2007;193:595-603.

7 Ishizaki T, Naito M, Fujisawa K, Maekawa M, Watanabe N, Saito Y, Narumiya S: p160ROCK, a Rho-associated coiled-coil forming protein kinase, works downstream of Rho and induces focal adhesions. FEBS Lett 1997;404:118-124.

8 Riento K, Ridley AJ: ROCKs: multifunctional kinases in cell behaviour. Nat Rev Mol Cell Biol 2003;4:446-456.

-9 Fukata M, Kaibuchi K: Rho-family GTPases in cadherin-mediated cell-cell adhesion. Nat Rev Mol Cell Biol 2001;2:887-897.

10 Zhang YM, Bo J, Taffet GE, Chang J, Shi J, Reddy AK, Michael LH, Schneider MD, Entman ML, Schwartz RJ, Wei L: Targeted deletion of ROCK1 protects the heart against pressure overload by inhibiting reactive fibrosis. FASEB J 2006;20:916-925.

- 11 Fu P, Liu F, Wang W, Huang XR, Entman ML, Schwartz RJ, Wei L, Lan HY: Signaling mechanism of renal fibrosis in unilateral ureteral obstructive kidney disease in ROCK1 knockout mice. J Am Soc Nephrol 2006;17:3105-3114.

12 Lan HY, Mu W, Nikolic-Paterson DJ, Atkins RC: A novel, simple, reliable, and sensitive method for multiple immunoenzyme staining: use of microwave oven heating to block antibody cross-reactivity and retrieve antigens. J Histochem Cytochem 1995;43:97-102.

13 Lan HY, Mu W, Tomita N, Huang XR, Li JH, Zhu HJ, Morishita R, Johnson RJ: Inhibition of renal fibrosis by gene transfer of inducible Smad7 using ultrasound-microbubble system in rat UUO model. J Am Soc Nephrol 2003; 14:1535-1548.

14 Zhou L, Fu P, Huang XR, Liu F, Lai KN, Lan HY: Activation of p53 Promotes renal injury in acute aristolochic acid nephropathy. J Am Soc Nephrol 2010;21:31-41.

15 Gojo A, Utsunomiya K, Taniguchi K, Yokota T, Ishizawa S, Kanazawa Y, Kurata H, Tajima N: The Rho-kinase inhibitor, fasudil, attenuates diabetic nephropathy in streptozotocininduced diabetic rats. Eur J Pharmacol 2007; 568:242-247.

16 Zhai XY, Nielsen R, Birn H, Drumm K, Mildenberger S, Freudinger R, Moestrup SK, Verroust PJ, Christensen EI, Gekle M: Cubilin- and megalin-mediated uptake of albumin in cultured proximal tubule cells of opossum kidney. Kidney Int 2000;58:15231533.

-17 Christensen EI, Birn H, Verroust P, Moestrup SK: Membrane receptors for endocytosis in the renal proximal tubule. Int Rev Cytol 1998; 180:237-284.

18 Sahali D, Mulliez N, Chatelet F, Dupuis R, Ronco P, Verroust P: Characterization of a 280-kDa protein restricted to the coated pits of the renal brush border and the epithelial cells of the yolk sac. Teratogenic effect of the specific monoclonal antibodies. J Exp Med 1988;167:213-218.

19 Lebeau C, Arlt VM, Schmeiser HH, Boom A, Verroust PJ, Devuyst O, Beauwens R: Aristolochic acid impedes endocytosis and induces DNA adducts in proximal tubule cells. Kidney Int 2001;60:1332-1342.

20 Norden AG, Lapsley M, Igarashi T, Kelleher CL, Lee PJ, Matsuyama T, Scheinman SJ, Shiraga $H$, Sundin DP, Thakker RV, Unwin RJ, Verroust P, Moestrup SK: Urinary megalin deficiency implicates abnormal tubular endocytic function in Fanconi syndrome. J Am Soc Nephrol 2002;13:125-133.

21 Obermüller N, Kränzlin B, Blum WF, Gretz N, Witzgall R: An endocytosis defect as a possible cause of proteinuria in polycystic kidney disease. Am J Physiol Renal Physiol 2001;280:F244-F253.

22 Remuzzi G, Bertani T: Pathophysiology of progressive nephropathies. N Engl J Med 1998;339:1448-1456.

$\checkmark 23$ Eddy AA: Proteinuria and interstitial injury. Nephrol Dial Transplant 2004;19:277-281.

24 Reich HN, Tritchler D, Cattran DC, Herzenberg AM, Eichinger F, Boucherot A, Henger A, Berthier CC, Nair V, Cohen CD, Scholey JW, Kretzler M: A molecular signature of proteinuria in glomerulonephritis. PLoS One 2010;5:e13451.

25 Wolf G, Schroeder R, Ziyadeh FN, Stahl RA: Albumin up-regulates the type II transforming growth factor- $\beta$ receptor in cultured proximal tubular cells. Kidney Int 2004;66: 1849-1858.

26 Komers R, Oyama TT, Beard DR, Tikellis C, $\mathrm{Xu}$ B, Lotspeich DF, Anderson S: Rho kinase inhibition protects kidneys from diabetic nephropathy without reducing blood pressure. Kidney Int 2011;79:432-442.

27 Peng F, Wu D, Gao B, Ingram AJ, Zhang B, Chorneyko K, McKenzie R, Krepinsky JC: RhoA/Rho-kinase contribute to the pathogenesis of diabetic renal disease. Diabetes 2008;579:1683-1692.

28 Tang S, Leung JC, Abe K, Chan KW, Chan LY, Chan TM, Lai KN: Albumin stimulates interleukin-8 expression in proximal tubular epithelial cells in vitro and in vivo. J Clin Invest 2003;111:515-527.

29 Shi J, Zhang L, Wei L: Rho-kinase in development and heart failure: insights from genetic models. Pediatr Cardiol 2011;32:297304.

30 Satoh K, Fukumoto Y, Shimokawa H: Rhokinase: important new therapeutic target in cardiovascular diseases. Am J Physiol Heart Circ Physiol 2011;301:H287-H296.

- 31 Fukushima M, Nakamuta M, Kohjima M, Kotoh K, Enjoji M, Kobayashi N, Nawata H: Fasudil hydrochloride hydrate, a Rho-kinase (ROCK) inhibitor, suppresses collagen production and enhances collagenase activity in hepatic stellate cells. Liver Int 2005;25:829-838.

- 32 Tada S, Iwamoto H, Nakamuta M, Sugimoto R, Enjoji M, Nakashima Y, Nawata H: A selective ROCK inhibitor, Y-27632, prevents dimethylnitrosamine-induced hepatic fibrosis in rats. J Hepatol 2001;34:529-536.

- 33 Patel S, Takagi KI, Suzuki J, Imaizumi A, Kimura T, Mason RM, Kamimura T, Zhang $\mathrm{Z}$ : RhoGTPase activation is a key step in renal epithelial mesenchymal transdifferentiation. J Am Soc Nephrol 2005;16:1977-1984.

34 Masszi A, Di Ciano C, Sirokmany G, Arthur WT, Rotstein OD, Wang J, McCulloch CA, Rosivall L, Mucsi I, Kapus A: Central role for Rho in TGF- $\beta_{1}$-induced $\alpha$-smooth muscle actin expression during epithelial-mesenchymal transition. Am J Physiol Renal Physiol 2003;284:F911-F924.

35 Hutchison N, Hendry BM, Sharpe CC: Rho isoforms have distinct and specific functions in the process of epithelial to mesenchymal transition in renal proximal tubular cells. Cell Signal 2009;21:1522-1531.

36 Nagatoya K, Moriyama T, Kawada N, Takeji M, Oseto S, Murozono T, Ando A, Imai E, Hori M: Y-27632 prevents tubulointerstitial fibrosis in mouse kidneys with unilateral ureteral obstruction. Kidney Int 2002;61: 1684-1695.

- 37 Kanda T, Wakino S, Hayashi K, Homma K, Ozawa Y, Saruta T: Effect of fasudil on Rhokinase and nephropathy in subtotally nephrectomized spontaneously hypertensive rats. Kidney Int 2003;64:2009-2019.

- 38 Teraishi K, Kurata H, Nakajima A, Takaoka M, Matsumura Y: Preventive effect of Y-27632, a selective Rho-kinase inhibitor, on ischemia/reperfusion-induced acute renal failure in rats. Eur J Pharmacol 2004;505: 205-211.

39 Nishikimi T, Akimoto K, Wang X, Mori Y, Tadokoro K, Ishikawa Y, Shimokawa H, Ono H, Matsuoka H: Fasudil, a Rho-kinase inhibitor, attenuates glomerulosclerosis in Dahl saltsensitive rats. J Hypertens 2004;22:1787-1796.

40 Haudek SB, Gupta D, Dewald O, Schwartz RJ, Wei L, Trial J, Entman ML: Rho kinase-1 mediates cardiac fibrosis by regulating fibroblast precursor cell differentiation. Cardiovasc Res 2009;83:511-518.

41 Shi J, Zhang YW, Summers LJ, Dorn GW 2nd, Wei L: Disruption of ROCK1 gene attenuates cardiac dilation and improves contractile function in pathological cardiac hypertrophy. J Mol Cell Cardiol 2008;44:551-560.

42 Lee DH, Shi J, Jeoung NH, Kim MS, Zabolotny JM, Lee SW, White MF, Wei L, Kim YB: Targeted disruption of ROCK1 causes insulin resistance in vivo. J Biol Chem 2009;284: 11776-11780. 